\title{
Work-related Asthma in Crop Farmers
}

\author{
Sasho Stoleski*, Jordan Minov, Jovanka Karadzinska-Bislimovska, Dragan Mijakoski, Aneta Atanasovska, \\ Dragana Bislimovska
}

Center for Respiratory Functional Diagnostics, Institute for Occupational Health - Skopje, WHO Collaborating Center, Ga²len Collaborating Center, Skopje, Republic of Macedonia

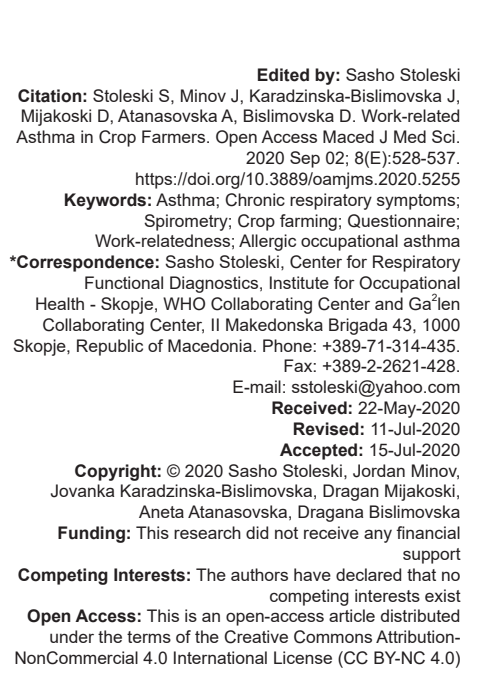

Abstract

AIM: The objective of the study was to evaluate the influence of occupational exposure on asthma development among crop farmers.

METHODS: A cross-sectional study was performed, comprising 87 crop farmers, and 80 office workers, matched by gender and age. Evaluation of subjects included completion of a standard questionnaire on chronic respiratory symptoms, spirometry tests, histamine challenge, serial peak expiratory flow rates (PEFR) measurements, and skin prick tests to occupational and common inhalant allergens.

RESULTS: The prevalence of chronic respiratory symptoms in the past 12 months was higher, while the mean values of spirometric parameters were lower in crop farmers. Sensitization to workplace and common inhalant allergens was similar in both groups, whereas frequencies of bronchial hyperresponsiveness (BHR) and asthma were nonsignificantly higher in crop farmers. The prevalence of allergic was significantly higher compared to non-allergic asthma in both groups. Asthma was registered in $8 \%$ of crop farmers and was significantly associated with atopy, and positive family history of asthma. Occupational allergic asthma (OA) was registered in $2.3 \%$ of crop farmers, while the frequency of work-aggravated asthma was $5.7 \%$. A causal relationship between workplace and asthma suggesting allergic OA, was documented in two crop farmers with asthma, based on serial PEFR monitoring, but specific workplace agent causing asthma in the affected subjects was not identified.

CONCLUSION: The obtained results can contribute in the detection of critical points for action, and serve as a predictive factor in the development of work-related asthma, indicating the need for reduction of adverse occupational exposures through adequate preventive measures, regular health examinations, obligatory use of respiratory protective equipment, and implementation of engineering controls.

\section{Introduction}

Work-related asthma(WRA) or work-attributable asthma is a form of asthma caused or triggered by specific agents and/or conditions at the workplace. This form of asthma is the most common lung disease in Europe and USA within past three decades, covering $20 \%-30 \%$ of all asthma cases in adults [1], [2].

WRA is asthma caused or triggered by specific agents and/or conditions in the workplace [3]. It is the most common lung disease related to work in the USA and Western Europe in the last three decades. The prevalence of WRA in subjects with adult asthma is $10-30 \%$ and in Republic of Macedonia, according to the survey in 2003 , it is $24.7 \%$ [4]. WRA is not unique and homogeneous entity, and includes several different types of asthma associated with the workplace having different pathogenic mechanisms.

Differentiating the various forms of WRA, being difficult sometimes is of particular importance having in mind their various medico-legal implications [5]. According to the etiology and pathogenetic mechanisms,
WRA is classified as occupational asthma (OA) and workaggravated or work-exacerbated asthma (WEA) [6].

$\mathrm{OA}$ is defined as new-onset asthma caused by agents and/or conditions attributable to a particular workplace environment and not by stimuli encountered outside the workplace [7], [8].

According to the results of several epidemiological studies, OA is about $5-20 \%$ of all asthma cases in adults. The incidence of $\mathrm{OA}$ is higher in developed countries than in developing countries (13$20 \%$ vs. $5-6 \%$ of all adult asthma cases) [9]. Data from several studies on the prevalence of allergic OA show that it affects $1-3 \%$ of workers in the food industry, 3-5\% of workers in the wood industry exposed to western red cedar dust, 7-9\% of bakers and workers from the food industry working with flour, $3-30 \%$ of workers working with laboratory animals, $5-30 \%$ of workers in the automotive industry that use isocyanates, about $46 \%$ of workers exposed to salts of platinum, and even $66 \%$ of workers involved in the production of detergents, and exposed to proteolytic enzymes [10], [11].

According to the results of allergic OA studies in the Republic of Macedonia, its prevalence is $1.6 \%$ 
in tea processors, $5.19 \%$ among the grinders of grain, $5.7 \%$ among the rice processing workers, $6.2 \%$ in the leather industry workers, and $2.3 \%$ and $1.3 \%$ in crop and dairy farmers, respectively [12], [13].

According to the etiopathogenetic mechanisms involved in its occurrence, $O A$ is classified as allergic $\mathrm{OA}, \mathrm{OA}$ with latency period or sensitizer-induced $\mathrm{OA}$, and non-allergic $\mathrm{OA}$, OA without latency period or irritant-induced OA [14].

Allergic OAalso called OAcaused by sensitizing agents or OA with a latency period is the most common type of OA (about $90 \%$ of all OA cases). This type of OA occurs after a latency period of occupational exposure, in which there is an allergic sensitization to specific workplace allergen, and development of chronic airway inflammation [8].

Non-allergic OA occurs after one or several exposure episodes to very high concentrations of respiratory irritants in the form of gases, vapors, or aerosols. According to the mechanisms of occurrence, the non-allergic OA includes several entities. Newonset asthma caused by an acute inhalation incident is called reactive airway dysfunction syndrome (RADS), which is the best-defined type of non-allergic OA [7].

WEA is defined as preexisting or new-onset asthma, allergic, or non-allergic, worsened by nonspecific stimuli from the work environment (respiratory irritants, cold and dry air, physical exertion, etc.) [14]. Since occupational exposure is not a direct and unique cause of this entity, WEA is not included in the List of Occupational Diseases in the countries worldwide, and this form of asthma does not have the legal implications of OA.

Occupational respiratory hazards in farming can exacerbate existing or lead to new-onset OA [15]. Pre-existing asthma can be exacerbated by exposure to dust or other substances, cold air, physical exertion, and many more [16]. Exposure to organic plant dust, for example, cereal dust, may exacerbate existing asthma or cause new-onset OA. Furthermore, crop farmers may become sensitized with grain dust mites in barns and barns and may develop OA [17], [18]. Irritant-induced OA can occur after inhalation of high concentrations of gases or vapors in farming, such as anhydrous ammonia and nitrogen oxides [19].

The two types of OA are included in the List of Occupational Diseases of the Republic of Macedonia, since 2004, labeled as allergic asthma caused by inhalation of substances appropriately identified as allergy-triggers and related to the type of work (304.06 A), and asthma caused by substances, scientifically proven as triggers of irritation associated with the workplace (304.06 B) [20].

\section{Subjects and Methods}

\section{Study design and setting}

A cross-sectional survey was conducted in the Center for Respiratory Functional Diagnostics by the team from the Institute for Occupational Health, Skopje - WHO Collaborating Center and GA2LEN Collaborating Center, within the period November 2018-May 2019, as a continuum of our investigation about work activities, exposure to respiratory hazards, and lung function impairment among crop farmers.

\section{Study sample}

First, we have calculated the representative study sample by the software program PEPI 4.04, with $95 \%$ confidence level and confidence interval \pm 5 .

To achieve this sample size, and keeping in mind possible selection and response bias, we have included 87 crop farmers and 80 matched office controls form a large scale agricultural enterprise. These groups were analyzed in our previous study as well [13].

\section{Subjects}

The institute's survey team examined 87 crop farmers (mean age $=53.4 \pm 7.8$ years and mean duration of exposure $22.9 \pm 7.8$ years). Being employed as crop farmers their main activities involved: Cultivating and harvesting crops, planting, digging, work with mechanized equipment, irrigation, cleaning premises, and pesticide handling. Furthermore, they were exposed to various respiratory hazards, such as dust, temperature amplitudes, fumes, vapors, and pesticides. Inclusion criteria for examined group (EG): Employed subjects with age range 18-64 years engaged in crop farming and exposed to at least one occupational respiratory hazard (dust, gases, fumes, and vapors).

Exclusion criteria for EG: Subjects younger than 18 or older than 64 years, and subjects not engaged in crop farming. To avoid selection bias and results' deviations, subjects with exposure to respiratory hazards outside crop farming were not included.

In addition, similar group of 80 office workers (mean age $=52.7 \pm 8.2$ years) matched for age, duration of employment, daily smoking, and socioeconomic status was studied as a control group (CG), without occupational exposure to respiratory hazards.

The subjects in both groups who were either diagnosed by physician to have some chronic respiratory disease (asthma, COPD, bronchiectasis, sarcoidosis, etc.), or treated with bronchodilators and/or corticosteroids were not included in the study. Furthermore, subjects in whom spirometry testing was contraindicated were not taken into a count. 
The study protocol was approved by the Institute's Ethics Committee; every examined subject was informed and gave written consent before any involvement in the survey.

\section{Questionnaire}

All study subjects were interviewed by the standardized questionnaire, including questions on work history, respiratory symptoms in the past 12 months, and smoking habits.

Chronic respiratory symptoms in the past 12 months (cough, phlegm, dyspnea, wheezing, and chest tightness) were obtained using the European Community for Coal and Steel questionnaire (ECCS-87), and the European Community Respiratory Health Survey (ECRHS) questionnaire [21], [22].

Classification of smoking status was done according to the World Health Organization guidelines on definitions of smoking status [23].

Daily smoker was defined as a subject who smoked at the time of the field survey at least once a day, except on days of religious fasting. Lifetime cigarette smoking and daily mean of cigarettes smoked in daily smokers were also assessed. Pack-years smoked were calculated according to the actual recommendations [24].

Ex-smoker was defined as a formerly daily smoker, who no longer smokes.

Passive smoking or exposure to environmental tobacco smoke was defined as the exposure of a person to tobacco combustion products from smoking by others [25].

\section{Skin prick tests (SPT) to standard inhalant and occupational allergens}

The atopic status of subjects diagnosed with asthma was determined by SPT to standard inhalant allergens: Birch pollen (Betula spp.), grass mixed pollen, tree mixed pollen, plantain (Plantago lanceolata), Dermatophagoides pteronyssinus, dog hair, cat fur, and feathers mixed. The sensitization to occupational allergens was evaluated by specific allergens related to crop farming (wheat, corn, rye, etc.).

SPT to workplace allergens were performed on the volar part of the forearm using commercial allergen extracts (Torlak, Serbia). All tests had positive $(1 \mathrm{mg} / \mathrm{mL}$ histamine) and negative (saline $0.9 \%$ ) controls. SPT were considered positive if the mean wheal diameter $20 \mathrm{~min}$ after allergen application was at least $3 \mathrm{~mm}$ or larger [26].

\section{Baseline spirometry}

Each study subject underwent spirometry testing, performed by spirometer Ganshorn SanoScope
LF8 (Ganshorn Medizin Electronic GmbH, Germany). We were measuring forced vital capacity (FVC), forced expiratory volume in one second $\left(\mathrm{FEV}_{1}\right), \mathrm{FEV}_{1} / \mathrm{FVC}$ ratio, and maximal expiratory flow at $50 \%, 75 \%$, and $25-75 \%$ of FVC (MEF ${ }_{50}, \mathrm{MEF}_{75}$, and $\mathrm{MEF}_{25-75}$, respectively), by recording the best result from three measurements of the $\mathrm{FEV}_{1}$ values within $5 \%$ of each other. The results were given as percentages of the predicted values according to the ECCS norms. The spirometry results were reported as percents of their predicted values due to the current European Respiratory Society (ERS) and American Thoracic Society (ATS) recommendations including reproducibility and acceptability [27].

\section{Histamine challenge test}

BHR was assessed by the histamine challenge test which was performed according to the actual ERS/ATS recommendations [28], [29]. For this purpose, concentrations of $0.5,1,2,4$, and $8 \mathrm{mg} / \mathrm{mL}$ histamine (Torlak, Serbia) were prepared by dilution with buffered saline. Afterward, the doses of aerosol generated by Pari LC nebulizer with output rate $0.17 \mathrm{~mL} / \mathrm{min}$ were inhaled through mouthpiece. Subjects inhaled increasing concentrations of histamine using a tidal breathing method until $\mathrm{FEV}_{1}$ fell by more than $20 \%$ of its baseline value (provocative concentration $20-\mathrm{PC}_{20}$ ) or until reaching the highest concentration.

BHR was categorized according to the ATS recommendations, as moderate to severe $\mathrm{BHR}$ $\left(\mathrm{PC}_{20}<1.0 \mathrm{mg} / \mathrm{mL}\right)$, mild BHR $\left(\mathrm{PC}_{20}=1.0-4.0 \mathrm{mg} / \mathrm{mL}\right)$, and borderline BHR ( $\left.\mathrm{PC}_{20}=4.0-8.0 \mathrm{mg} / \mathrm{mL}\right)$ [29].

\section{Diagnostic criteria for asthma}

According to the actual recommendations by global initiative for asthma, asthma in subjects with normal spirometry findings is defined as symptomatic BHR with $\mathrm{PC}_{20} \leq 4 \mathrm{mg} / \mathrm{mL}$, whereas in subject with respiratory impairment with positive bronchodilator test [30].

\section{Serial PEFR measurement}

Serial PEFR measurements were performed among crop farmers with asthma using a PEFR-meter asmaPLAN (Vitalograph Ltd, Ireland), according to the ERS recommendations [31]. To provide an adequate representation of days at work (exposure period) and days away from work (elimination period), positive record included 2 weeks at work and 2 weekends away from work, and negative record included two work periods separated by at least 10 days away from work. Serial PEFR measurement was carried out by crop farmers who were well instructed how to use the PEFR meter, and perform the monitoring. They were instructed to take three readings and record the highest reading only if the two best readings were within $20 \mathrm{~L} / \mathrm{min}$ apart. Readings were taken 4 times a day at approximately 
similar times at work and away from work. The readings were interpreted by analyzing diurnal PEFR variations. The test was considered positive when PEFR varied $20 \%$ or more (calculated as maximum PEFR subsided by minimum PEFR, and divided by maximum PEFR) during working days, as opposed to days off.

\section{Diagnostic criteria for $O A$}

OA was diagnosed according to the criteria proposed by the American College of Chest Physicians (ACCP) [1]. The subjects were considered having allergic $O A$ in the cases of diagnosed asthma $(A)$, the onset of symptoms after starting work at the current job position (B), the association between symptoms of asthma and work (C), workplace exposure to an agent or process known to give rise to OA (D1), and significant work-related changes in PEFR (D2) or significant work-related changes in non-specific bronchial responsiveness (D3). The diagnosis and definition of RADS included criteria A, B, C, D1, and D5 (onset of asthma with a clear association with symptomatic exposure to a workplace irritant).

\section{Statistical analysis}

The obtained data were analyzed using Statistica for Windows version 7. Continuous variables were expressed as mean values with standard deviation and categorical variables as numbers and percentages. The Chi-square test (or Fisher's exact test) was used for testing differences in the prevalence of respiratory symptoms, while the comparison of spirometric measurements was performed by independent-samples t-test. $p<0.05$ was considered statistically significant. Logistic and multiple linear regression analysis were used to assess the risk for the development of chronic respiratory symptoms related to workflow characteristics in crop farmers, and lung function impairment, adjusted for age, exposure duration, and smoking habit. Study variables were checked for normality by KolmogorovSmirnov and Shapiro-Wilk's W test.

\section{Results}

An overview of overall and demographic characteristics of the study subjects is shown in Table 1.

Neither diagnose of any chronic respiratory non-occupational disease (sarcoidosis, and tuberculosis) established before the study, nor treatment with oral corticosteroids, bronchodilators, antihistamines, or any other medications that could potentially influence the functional and clinical findings were reported by the study subjects.
Table 1: Demographics of the study subjects [13]

\begin{tabular}{lll}
\hline Variable & Crop farmers $(\mathrm{n}=87)$ & Office workers $(\mathrm{n}=80)$ \\
\hline Gender/M/F ratio & 3.6 & 2.7 \\
Age range (years) & $20-63$ & $21-64$ \\
Age (years) & $53.4 \pm 7.8$ & $52.7 \pm 8.2$ \\
BMI (kg/m ${ }^{2}$ ) & $25.6 \pm 3.5$ & $26.2 \pm 3.7$ \\
Duration of employment (years) & $28.2 \pm 8.9$ & $25.3 \pm 9.8$ \\
Duration of exposure & $22.9 \pm 7.8$ & $/$ \\
Daily smokers & $45(51.7 \%)$ & $39(48.7 \%)$ \\
Life-time smoking (years) & $19.7 \pm 8.1$ & $19.2 \pm 7.8$ \\
Cigarettes/day & $15.4 \pm 7.3$ & $14.8 \pm 7.2$ \\
Pack-years smoked & $13.1 \pm 4.8$ & $12.9 \pm 4.9$ \\
Ex-smokers & $12(13.8 \%)$ & $12(15 \%)$ \\
Passive smokers & $11(12.6 \%)$ & $8(16 \%)$ \\
\hline Numerical data are expressed as mean value with standard deviation; frequencies as number and
\end{tabular}

percentage of study subjects with certain variable. BMI: Body mass index, kg: Kilogram; m: Meter.

Table 2 gives an overview of the frequency of asthmatic symptoms (cough, dyspnea, wheezing, and/or chest tightness), positive BD tests, positive histamine challenge tests with $\mathrm{PC}_{20} \leq 4 \mathrm{mg} / \mathrm{mL}$, as well as asthma prevalence among subject in EG and CG.

Table 2: Frequency of asthma symptoms, positive BD tests, positive histamine challenge tests with $\mathrm{PC}_{20} \leq 4 \mathrm{mg} / \mathrm{mL}$ and asthma among subjects in EG and CG

\begin{tabular}{lll}
\hline Variable & EG $(\mathrm{n}=87)$ & $\mathrm{CG}(\mathrm{n}=80)$ \\
\hline Respiratory symptoms in the past 12 months & $26(29.9 \%)$ & $16(20 \%)$ \\
Positive BD test & $15(17.2 \%)$ & $8(10 \%)$ \\
Positive histamine challenge tests with $\mathrm{PC}_{20} \leq 4 \mathrm{mg} / \mathrm{mL}$ & $9(10.3 \%)$ & $5(6.3 \%)$ \\
Asthma & $7(8 \%)$ & $4(5 \%)$ \\
\hline Data are given as number and percent of subjects with certain variable. EG: Examined group, CG: Control \\
group.
\end{tabular}

The frequency of allergic asthma is nonsignificantly higher in crop farmers than in controls (Figure 1).

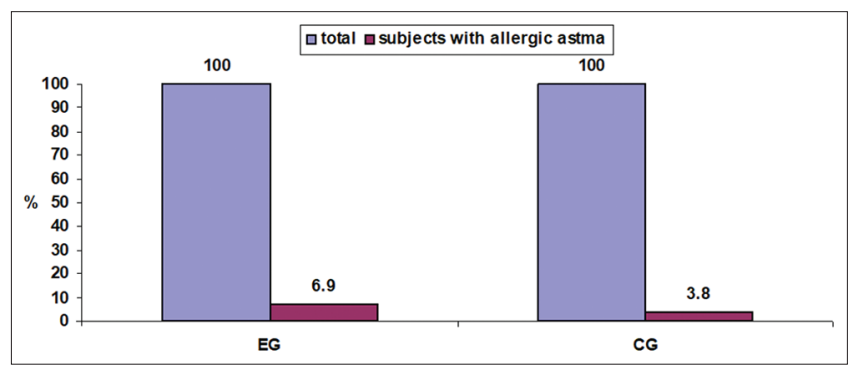

Figure 1: Distribution of allergic asthma among subjects in examined group and control group

According to the upper figure, the risk for allergic asthma development is non-significantly higher in crop farmers (OR $=1.90$ [0.4-9.99] Cl 95\%), compared to controls.

The frequency of allergic asthma is significantly higher compared to non-allergic in both groups (Figure 2).

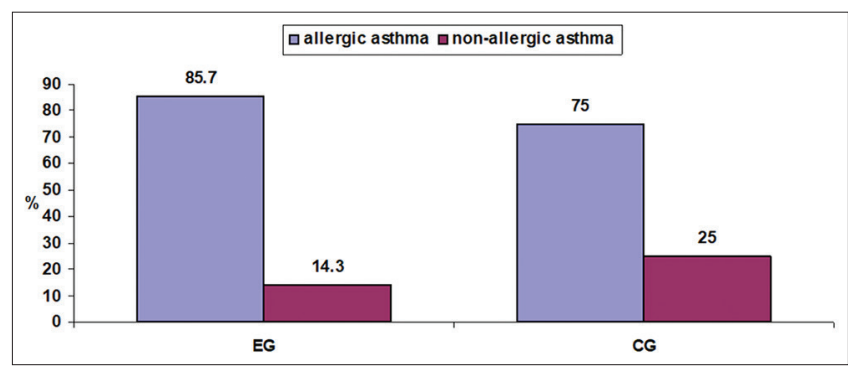

Figure 2: Distribution of allergic and non-allergic asthma among asthmatic subjects in examined group and control group

The frequency of subjects with allergic asthma who is sensitized to occupational allergens (wheat, corn, rye, cow hairs, and molds) is similar in crop farmers and 
controls (Figure 3). Frequency of subjects sensitized to standard inhalant allergens is non-significantly higher in crop farmers with allergic asthma compared to controls.

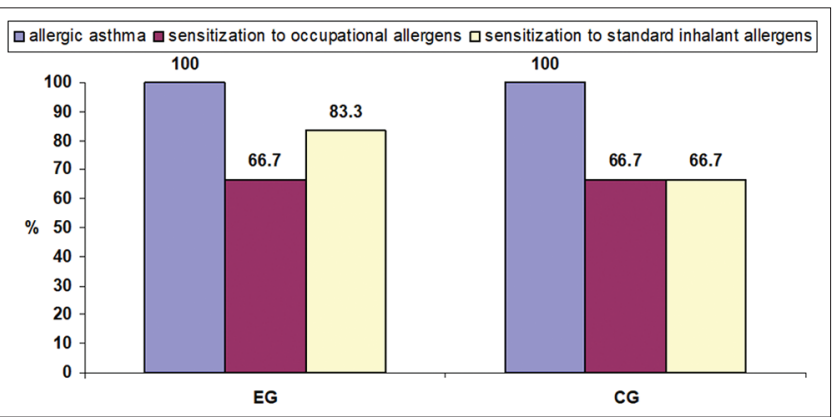

Figure 3: Frequency of sensitization to occupational and standard inhalant allergens in subjects of examined group and control group with asthma

The risk of sensitization to occupational allergens is non-significantly higher among crop farmers with allergic asthma (OR $=1.88$ [0.29-15.25] Cl 95\%), compared to office controls.

The risk of sensitization to standard inhalant allergens is non-significantly higher among crop farmers with allergic asthma $(\mathrm{OR}=2.38$ [0.39-18.28] Cl 95\%), compared to controls.

In subjects with allergic asthma from EG, the most common is sensitization to $D$. pteronyssinus, grass and tree mixed pollen, and birch pollen, while among subjects with allergic asthma from CG, the most common is sensitization to grass and tree mixed pollen, and D. pteronyssinus (Table 3). The difference in the frequency of sensitization to individual allergens in subjects with allergic asthma from EG and CG is non-significant.

Table 3: Sensitization to certain allergens among subjects with allergic asthma in EG and CG

\begin{tabular}{lll}
\hline Type of allergens & \multicolumn{2}{c}{ Subjects with allergic asthma } \\
\cline { 2 - 3 } & EG $(\mathrm{n}=6)$ & CG $(\mathrm{n}=3)$ \\
\hline Birch pollen & $3(50 \%)$ & $1(33.3 \%)$ \\
Grass mixed pollen & $4(66.7 \%)$ & $3(100 \%)$ \\
Tree mixed pollen & $3(50 \%)$ & $2(66.7 \%)$ \\
Plantain pollen & $2(33.3 \%)$ & 0 \\
Dermatophagoides pteronyssinus & $5(83.3 \%)$ & $2(66.7 \%)$ \\
Dog hair & $2(33.3 \%)$ & $1(33.3 \%)$ \\
Cat fur & $1(16.7 \%)$ & $1(33.3 \%)$ \\
Feathers mixed & $1(16.7 \%)$ & 0 \\
\hline Data are given as number and percent of subjects with certain variable. EG: Examined group, CG: Control
\end{tabular}
group

All crop farmers diagnosed with asthma report worsening of symptoms during or after work, and their improvement or withdrawal in the absence of work (weekends, sick leave, and vacations). CG subjects diagnosed with asthma do not indicate a relationship between the disease symptoms and work.

In EG subjects diagnosed with asthma, the evaluation for WRA and its forms was performed according to the diagnostic criteria of ACCP, i.e., diagnostic criteria $A, B, C$, and $D(1-5)$.

Diagnostic criteria A (diagnosed asthma) and $C$ (data on worsening symptoms at work and their improvement while away from work) are present in all EG asthma subjects. Data on the presence of symptoms before starting work at the current job position were obtained from three EG subjects; while four EG respondents developed symptoms after starting work at the current job position (diagnostic criterion B). The diagnostic criterion D1 (occupational exposure of the agent or process that may cause $O A$ ) is present in all EG subjects with asthma. None of the EG subjects with asthma developed the first onset of asthmatic symptoms within $24 \mathrm{~h}$ after exposure to a high concentration of irritating substance at the current job position (diagnostic criterion D5).

The type of association of asthma and work has been evaluated by exposure and elimination tests with serial PEFR measurements (diagnostic criterion D2).

The results of exposure and elimination tests by serial PEFR measurements in crop farmers with asthma are shown in Table 4. A significant decrease in the mean PEFR values and mean diurnal PEFR variations are registered in two subjects (Case 1 and Case 3 ) of crop farmers with asthma in the exposure periods compared to the elimination periods (Table 4).

Positive and negative diagnostic criteria for certain form of WRA in crop farmers are shown in Table 5.

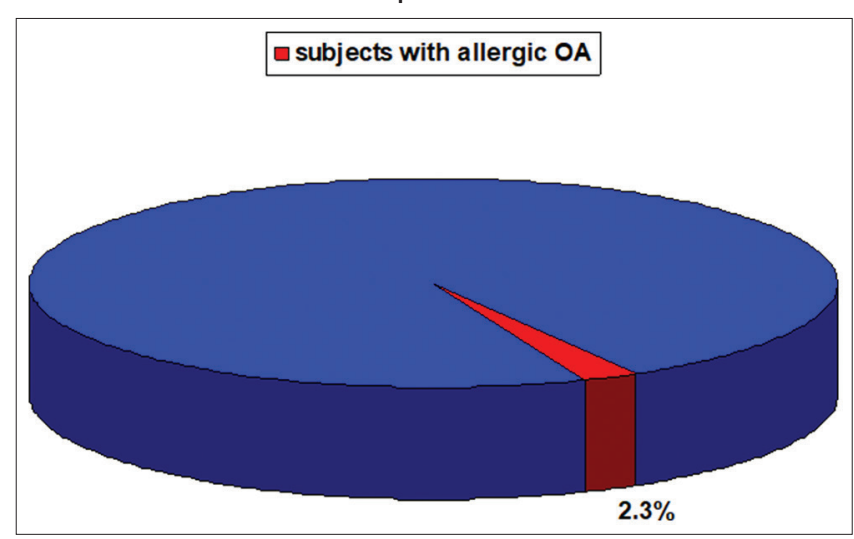

Figure 4: Frequency of allergic occupational allergic asthma among crop farmers

The diagnostic criteria for allergic OA $(A+B+C+D 2)$ are met by two subjects, namely, Case 1 and Case 3 . The diagnostic criteria for RADS $(A+B+$ $C+D 5)$ are not met by any of the evaluated EG subjects diagnosed with asthma. The frequency of allergic OA in crop farmers was $2.3 \%$ (Figure 4), i.e., allergic OA was found in $28.6 \%$ of EG subjects with asthma (Figure 5).

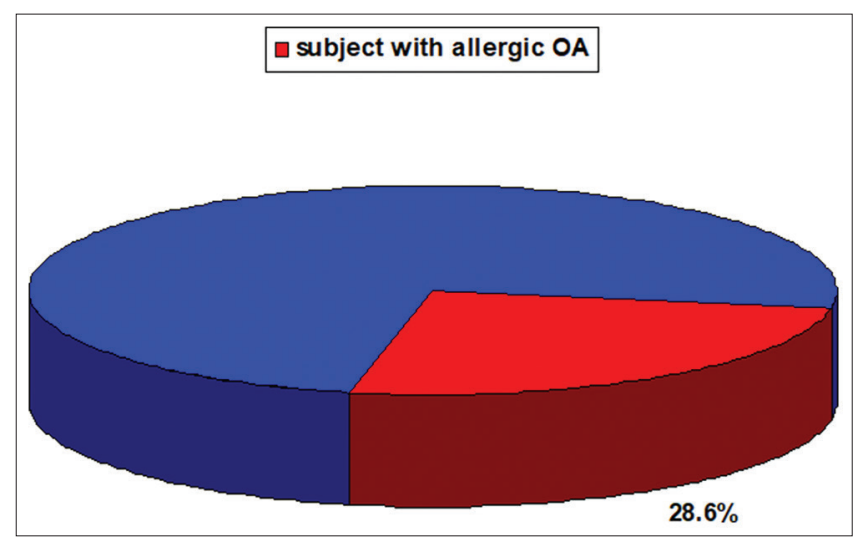

Figure 5: Frequency of allergic occupational allergic asthma among crop farmers with asthma 
Table 4: Mean PEFR values and mean diurnal PEFR variations in crop farmers with asthma in the exposure and elimination periods

\begin{tabular}{|c|c|c|c|c|c|c|}
\hline Cases & $\begin{array}{l}\text { Mean PEFR values } \\
\text { (L/min) exposure (at work) }\end{array}$ & $\begin{array}{l}\text { Mean PEFR values (L/min) } \\
\text { elimination (away from work) }\end{array}$ & $\mathrm{p}^{*}$ & $\begin{array}{l}\text { Mean diurnal PEFR variations (\%) } \\
\text { exposure (at work) }\end{array}$ & $\begin{array}{l}\text { Mean diurnal PEFR variations (\%) } \\
\text { elimination (away from work) }\end{array}$ & $\mathrm{p}^{*}$ \\
\hline 1 & 235 & 305 & $p<0.05$ & 26.7 & 11.3 & $p<0.05$ \\
\hline 2 & 395 & 385 & NS & 19.3 & 15.8 & NS \\
\hline 3 & 230 & 315 & $\mathrm{p}<0.05$ & 25.6 & 12.5 & $p<0.05$ \\
\hline 4 & 315 & 305 & NS & 24.3 & 20.1 & NS \\
\hline 5 & 310 & 318 & NS & 18.7 & 16.9 & NS \\
\hline 6 & 306 & 312 & NS & 16.2 & 15.6 & NS \\
\hline 7 & 312 & 309 & NS & 25.3 & 20.6 & NS \\
\hline
\end{tabular}

Table 5: Diagnostic criteria on WRA among crop farmers with asthma

\begin{tabular}{lllllll}
\hline Cases & A & B & C & D1 & D2 & D5 \\
\hline 1 & + & + & + & + & + & - \\
2 & + & + & + & + & - & - \\
3 & + & + & + & + & + & - \\
4 & + & - & + & + & - & - \\
5 & + & + & + & + & - & - \\
6 & + & - & + & + & - & - \\
7 & + & - & + & + & - & - \\
\hline
\end{tabular}

Diagnostic criteria for work-aggravated or work-exacerbated asthma $(A+C)$ are met by five crop farmers with asthma (not taking into account two farmers with diagnosed occupational asthma). Three of them are likely to have pre-existing asthma that was aggravated by work, and two of them have new-onset asthma worsened at work. The frequency of work-aggravated asthma among crop farmers is $5.7 \%$ (Figure 6).

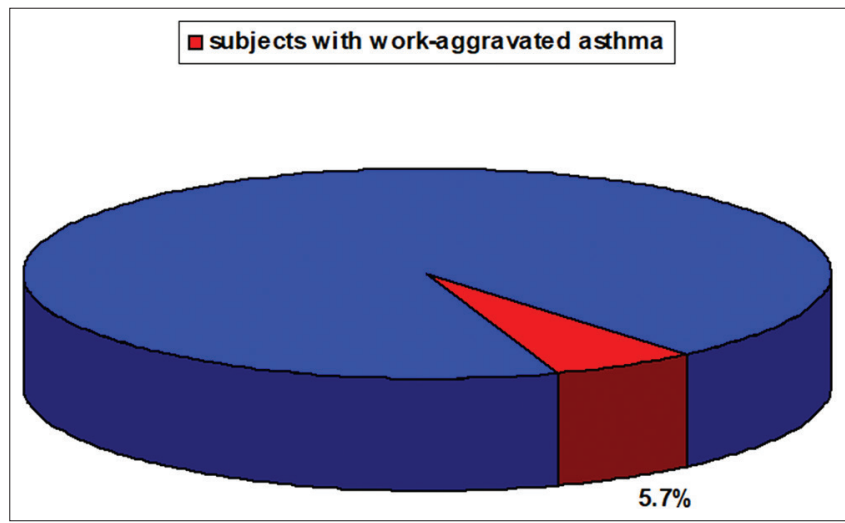

Figure 6: Frequency of work-aggravated asthma among crop farmers

\section{Discussion}

The prevalence of asthma (diagnosed as symptomatic BHR with $\mathrm{PC}_{20} \leq 4 \mathrm{mg} / \mathrm{mL}$ in subjects with a normal spirometric finding or a positive BD test in subjects with impaired respiratory function) in EG subjects in the current study is $8 \%$, which is non-significantly higher than the prevalence of asthma in CG subjects (5\%). The obtained results are similar to the results of the multi-centric study for allergic diseases in Macedonia by Cvetanov et al. The prevalence of asthma in the mentioned study was $5.4 \%$ among all examined subjects, with office workers receiving a $4.8 \%$ prevalence of the disease, and workers with specific occupational exposure, i.e., workers in the textile and pharmaceutical industries (from plants for production of chemicals and finished drugs), construction workers, utilities, furniture production, paints, and varnishes, had the prevalence of $5.8 \%$. The highest prevalence of asthma is registered in workers in the pharmaceutical industry $(8.7 \%)$, the textile industry $(7.2 \%)$ and workers in the production of paints and varnishes $(6.2 \%)$ [4]. The results about the asthma prevalence from the current study correlate with those of Minov et al. in a study dedicated to asthma in pharmaceutical workers [12].

Two studies have been performed within ECRHS, in Spain and New Zealand, which investigate the impact of occupational exposure on asthma development [32]. Significantly higher risk of asthma compared to office workers was recorded in farmers $(O R=4.16)$, while non-significantly higher risk was registered in laboratory technicians, workers in the chemical and wood industries, car dealers, and rubber and plastics workers. The risk of asthma in a set of workers in food production other than bakeries is nonsignificantly higher than in office workers $(\mathrm{OR}=1.83$ $\mathrm{Cl}$ 95\% 0.32-8.34), similar to the results of a study by Kogevinas et al. and our current study [33]. The data on the highest risk of developing asthma in farmers are explained by the characteristic occupational exposure among farmers in New Zealand, i.e., the specific mixture of numerous animal (domestic animals and birds), plant (different types of vegetables, fruits, and cereals) and synthetic allergens (insecticides, fungicides, rhodenticides, etc.) [34].

The association of asthma and sensitization to the examined occupational allergens is non-significant in both groups, while the significant association of asthma with atopy has been reported only in crop farmers. According to the results of the mentioned study of Kogevinas et al., the risk of asthma in subjects with specific occupational exposure is about 3 times higher in subjects with atopy than in non-atopic individuals $(\mathrm{OR}=3.25)$ [32]. Furthermore, the results of the study of de Meer et al. with 1906 examinees on the association of asthma in subjects with occupational exposure to organic and inorganic dust with atopy (detected by SPT on eight standard aeroallergens) and smoking, suggest a significant association between asthma and atopy in persons exposed to organic dust, suggesting interaction between atopy and exposure to organic dust in the asthma development [35]. 
Allergic asthma is present in $85.7 \%$ crop farmers $75 \%$ controls, which is a frequency similar to the literature data. The results of the studies on the prevalence of non-allergic asthma indicate a frequency of about $30 \%$ in studies with hospitalized respondents with asthma, i.e., 15-20\% in studies with respondents from the general population [36]. The sensitization of the individual standard aeroallergens in the subjects of both groups is dominated by $D$. pteronyssinus. Similar results were obtained in the general population surveys in our country such as the studies of KaradzinskaBislimovska et al. and Cvetanov et al. [4], [37]. Furthermore, the importance of sensitization to $D$. pteronyssinus as a risk factor for asthma occurrence has been registered in several local studies and in the global analysis of ECRHS data [38].

Occupational exposure can reactivate asthma in people who have been asymptomatic for years, worsen existing asthma, or cause new-onset asthma in a previously healthy person. WRA is a broad term that includes OA (asthma caused by sensitization to a specific agent from the workplace, i.e., allergic OA, and asthma caused by inhalation of respiratory irritants in the workplace in excessive concentrations, i.e., irritant-induced asthma or RADS) and all other cases of asthma that is exacerbated but not caused by specific occupational exposure (work-exacerbated asthma). According to the legislation in many countries worldwide, allergic OA and RADS are occupational diseases, i.e., their diagnosis entails mandatory discontinuation of exposure and compensation by the appropriate health insurance fund, while work-exacerbated or workaggravated asthma is not an occupational disease. The situation is complicated by the possibility of newonset reported asthma that is worsened at work or the occurrence of allergic OA in a person with previously diagnosed non-occupational asthma, especially having in mind the variable and often unpredictable clinical course of the disease [39].

The finnish study by Karjalainen et al. with subjects within age range 20-44, indicates that WRA accounts for $29 \%$ of adult asthma in men and $16 \%$ in women [40]. According to the results of a Canadian study by Johnson et al. in subjects of the same age group, $18 \%$ of cases of adult asthma are WRA [41]. Using meta-analysis of studies with the highest methodological standards, Blanc et al. estimated the prevalence of WRA as $15 \%$ of cases of adult asthma [42]. The study of Blanc et al. within ECRHS in Sweden with 2065 subjects indicates incapacity for work (change or loss of job) in $22 \%$ of subjects with asthma, with incapacity for work been correlated with the degree of dust concentration at the workplace. The risk of incapacity for work is high in jobs with moderate dust air pollution (bakers, workers in the wood, shoe and food industries, etc.), and very high in jobs with a high degree of dust air pollution (farmers, miners, stone cutters, parquet flooring workers, etc.) [43].
The prevalence of WRA in the current study is 8\% within EG. All EG subjects diagnosed with asthma indicated a relationship of symptoms with work, i.e., their worsening during or after work, and improvement or complete withdrawal during weekends, sick leaves, and vacations. The result is within the range of expectations with regard to their "dusty occupation" according to Karjalainen, which according to the ECRHS can be classified as a moderate degree dusty occupation [42], [44]. On the other hand, according to Nemery, a very high diagnostic value for WRA is the work history data for improvement or withdrawal of symptoms in the absence of work, apart from the data about their worsening during or after work [45]. None of the CG subjects diagnosed with asthma indicated worsening of asthma related to work.

The evaluation of the type of asthma associated with workplace, that is, differentiation of WRA was performed according to the diagnostic criteria of ACCP [46], with all crop farmers with asthma being tested during exposure and elimination period with serial PEFR-measurements. In the current study, two EG subjects were registered with positive exposure and elimination tests with serial PEFR-measurements, that is, significantly lower average PEFR values and significantly higher average diurnal PEFR variations over the exposure period compared to the elimination period, which refers to allergic asthma caused by a workplace sensitizer. Within other crop farmers with asthma, results from exposure and elimination tests are negative, which eliminates the possibility of allergic OA. None of the subjects had information on the onset of asthma with a clear association with symptomatic irritant exposure at the workplace, that is, the diagnostic criterion for RADS, which is in favor of asthma exacerbated at work in the remaining five subjects with asthma within EG. The prevalence of allergic OA in crop farmers of $2.3 \%$ in our study correlates with the results of the study of Minov et al. among workers in the pharmaceutical industry (herbal tea processors and medicines production) indicating the prevalence of $1.6 \%$ for allergic OA [12]. According to the results of other studies of allergic OA in Macedonia, its prevalence is $5.19 \%$ for grain millers, $5.7 \%$ for rice processing workers, and $6.2 \%$ for leather workers [4], [12]. The tests for evaluating the type and association of asthma with the workplace, that is, exposure and elimination tests with serial spirometry, serial PEFR-monitoring, and serial histamine/methacholine challenge tests, have certain sensitivity and specificity.

The results of the exposure and elimination tests by serial PEFR-monitoring and serial histamine/ methacholine challenge tests are complementary, which has also been confirmed in other studies [47], [48].

Work-aggravated asthma or work-exacerbated asthma is the most common form of WRA with massive and potentially preventable medical and socioeconomic consequences [49]. In the current study, the prevalence 
of work-aggravated asthma is $5.7 \%$ among crop farmers. Despite data on high financial costs, frequent absences from work, and impaired quality of life, few data from a limited number of studies are encountered for the prevalence of work-aggravated asthma in the literature. The reason for this is the inability to objectify the disease worsening at the workplace, or the fact that the diagnosis of asthma worsened at work is based on the data of the subject with asthma for higher frequency and intensity of symptoms related to the workplace, as well as exclusion of the occupational types of the disease [39]. According to the results from the study of Tarlo et al., OA is the most common form of WRA with a prevalence of at least twice the prevalence of OA [50]. In the study of Saarinen et al. with 2000 adults with asthma, excluding persons with $\mathrm{OA}$, exacerbation of work-related symptoms was reported by $40 \%$ of examined subjects [51].

As in the other cases of asthma diagnosed in the current study, none of the crop farmers with workaggravated asthma, reported the previous medical diagnosis of the disease. Under-diagnosis of WRA, as well as under-diagnosis of asthma in general, is a problem that is detected by several studies, and reasons for this can be allocated both in patients and doctors [52]. Patients may ignore the disease symptoms or minimize their significance because of the rare occurrence or presence of mild symptoms, low health culture, and the fear of losing their jobs if diagnosed with this particular disease. However, it is a global problem, in whose resolution satisfactory results are still not being achieved [53], [54].

This study has certain limitations. Namely, relatively small number of subjects in the study groups, and lack of ambient monitoring could aggravate a clear relationship between occupational exposure and respiratory impairment among crop farmers. In addition, testing with more types of allergens and in vitro testing could better present sensitization to workplace allergens and its implications to respiratory impairment, as well as the relationship to data obtained from serial PEFR measurements and challenge tests, making it possible to compare different methods in the detection of allergic OA in crop farmers.

\section{Conclusion}

The data obtained revealed a higher prevalence of respiratory symptoms and spirometric changes in crop farmers compared to controls. Sensitization to workplace and common inhalant allergens was similar in both groups, whereas frequencies of BHR and asthma were non-significantly higher in crop farmers. The prevalence of allergic was significantly higher compared to nonallergic asthma in both groups. A causal relationship between workplace and asthma, suggesting allergic OA, was documented in two crop farmers with asthma, based on serial PEFR monitoring, but specific workplace agent causing asthma in the affected subjects was not identified. None of the crop farmers with asthma met the criteria for definition of RADS.

This knowledge should further contribute in detection of critical points for action, and serve as a predictive factor in the development of respiratory diseases, within the diagnostic algorithm focused on respiratory health assessment. It also indicates the need for reduction of adverse occupational exposures through adequate preventive measures, regular health examinations, obligatory use of respiratory protective equipment, and implementation of engineering controls.

\section{References}

1. Tarlo SM, Balmes J, Balkisson R, Beach J, Beckett W Bernstein D, et al. Diagnosis and management of work-related asthma. American college of chest physicians consensus statement. Chest. 2008;134(3):15-41.

PMid:18779187

2. Tarlo SM, Lemiere C. Occupational asthma. N Engl J Med. 2014;370(7):640

PMid:24521110

3. Dykewicz MS. Occupational asthma: Current concepts in pathogenesis, diagnosis, and management. J Allergy Clin Immunol. 2009;123:519.

PMid:19281900

4. Cvetanov V. Allergic Diseases in Republic of Macedonia Skopje: Institute for Occupational Health, Macedonian Society of Basic and Clinical Immunology, Allergology; 2006.

5. Henneberger PK, Redlich CA, Callahan DB, Harber P, Lemière $\mathrm{C}$, Martin $\mathrm{J}$, et al. An official American thoracic society statement: Work-exacerbated asthma. Am J Respir Crit Care Med. 2011;184(3):368. https://doi.org/10.1164/rccm.812011st PMid:21804122

6. Lemière $\mathrm{C}$, Boulet LP, Chaboillez $\mathrm{S}$, Forget $\mathrm{A}$, Chiry $\mathrm{S}$, Villeneuve $\mathrm{H}$, et al. Work-exacerbated asthma and occupational asthma: Do they really differ? J Allergy Clin Immunol. 2013;131(3):704. https://doi.org/10.1016/j.jaci.2012.08.024 PMid:23058644

7. Bernstein IL, Bernstein DI, Chan-Yeung M, Malo JL. Definition and classification of asthma in the workplace. In: Malo JL, Chan-Yeung M, Bernstein DI, editors. Asthma in the Workplace. $4^{\text {th }}$ ed. Boca Raton, FL: CRC Press; 2013. p. 1-5. https://doi. org/10.1201/b15116-2

8. Cartier A, Bernstein D. Occupational Asthma: Definitions, Epidemiology, Causes and Risk Factors. United States; UpToDate; 2019.

9. Toren K, Blanc J. Asthma caused by occupational exposures is common: A systematic analysis of the population attribute able fraction. BMC Pulm Med. 2009;9:7. https://doi. org/10.1186/1471-2466-9-7

PMid:19178702

10. Mapp CE, Boschetto P, Maestrelli P, Fabbri L. Occupational asthma. Eur Respir Crit Care Med. 2005;172(3):280-305. https://doi.org/10.1164/rccm.200311-1575so 


\section{PMid:15860754}

11. Janson C, Anto J, Burney P, Chinn S, De Marco R, Heinrich J, et al. The European community respiratory health survey: What are the main results so far? European community respiratory health survey II. Eur Respir J. 2001;18(3):598-611. https://doi. org/10.1183/09031936.01.00205801

\section{PMid:11589359}

12. Minov J, Karadzinska-Bislimovska J, Vasilevska K, Risteska-Kuc S, Stoleski S. Occupational asthma in subjects occupationally exposed to herbal and fruit tea dust. Arh Hig Rada Toksikol. 2007;58(2):211-21. https://doi.org/10.2478/ v10004-007-0016-4 PMid:17562605

13. Stoleski S, Minov J, Mijakoski D, Atanasovska A, Bislimovska D, Karadzinska-Bislimovska J. Specific work activities and exposure to respiratory hazards-predictors of lung function impairment among crop farmers. Open Access Maced J Med Sci. 2020;8:41-51. https://doi.org/10.3889/oamjms.2020.4641

14. Tarlo SM, Malo JL. An official ATS proceedings: Asthma in the workplace. Proc Am Thorac Soc. 2009;6(4):339-49. PMid:19675344

15. Schenker MB. Farming and asthma. Occup Environ Med. 2005;62(4):211-2.

PMid:15778250

16. Arif AA. Occupational exposures associated with work-related asthma and work-related wheezing among US workers. Am J Ind Med. 2003;44(4):368-76. https://doi.org/10.1002/ajim.10291 PMid:14502764

17. Chan-Yeung M, Malo JL. Table of major inducers of occupational asthma. In: Bernstein M, Chan-Yeung J, Malo L, Bernstein DI, editors. Asthma in the Workplace. New York: Marcel Dekker; 1993. p. 595-624. https://doi.org/10.1201/b15116

18. Beach J, Russel K, Blitz S, Hooton N, Spooner C, Lemiere C, et al. A systematic review of the diagnosis of occupational asthma. Chest. 2007;131(2):569-78. https://doi.org/10.1378/ chest.06-0492

PMid:17296663

19. Leduc D, Gris P, Lheureux P, Gevenois PA, DeVuyst P, Yernault PJ. Acute and long term respiratory damage following inhalation of ammonia. Thorax. 1992;47(9):755-7. https://doi. org/10.1136/thx.47.9.755

PMid:1440475

20. Official Gazette of R.M. Rulebook on the List of Occupational Diseases. Geneva: Official Gazette of R.M; 2004. p. 88.

21. Minette A. Questionnaire of the European community for coal and steel (ECSC) on respiratory symptoms. 1987-updating of the 1962 and 1967 questionnaires for studying chronic bronchitis and emphysema. Eur Respir J. 1989;2(2):165-77.

PMid:2703044

22. European Community Respiratory Health Survey. Variations in the prevalence of respiratory symptoms, self-reported asthma attacks, and use of asthma medication in the European respiratory health survey (ECRHS). Eur Respir J. 1996;9(4):68795. https://doi.org/10.1183/09031936.96.09040687

PMid:8726932

23. World Health Organization. Guidelines for Controlling and Monitoring the Tobacco Epidemic. Geneva: World Health Organization; 1998.

24. Smoking Pack-years; 2013. Available from: http://www. smokingpackyears.com/calculate. [Last accessed on 2020 Feb 15].

25. US Department of Health and Human Services. The Health Consequences of Smoking: Chronic Obstructive Pulmonary Disease. A report of the Surgeon General; 1984. Available from: http://www.profiles.nlm.nih.gov/ps/access/NNBCCS.pdf. [Last accessed on 2020 Feb 16].
26. van Kampen V, de Blay F, Folletti I, Kobierski P, Moscato G, Olivieri $\mathrm{M}$, et al. EAACl position paper: Skin prick testing in the diagnosis of occupational Type I allergies. Allergy. 2013;34:5804. https://doi.org/10.1111/all.12120

27. Quajner H, Tammeling GJ, Cotes JE, Pedersen OF, Peslin R, Yernault JC. Lung volumes and forced ventilatory flows: Official statement of the European respiratory society. Eur Respir J. 1993;16(1):1-100.

28. Sterk PJ, Fabbri LM, Quanjer PH, Cockcroft DW, O’Byrne PM, Anderson SD, et al. Standardized challenge testing with pharmacological, physical and sensitizing stimuli in adults. Report working party for the standardization of lung function tests. European community for steel and coal. Official statement of the European respiratory society. Eur Respir J. 1993;6(S16):53-83. https://doi.org/10.1183/09041950.053s1693

PMid:8499055

29. Crapo RO, Casaburi R, Coates AL, Enright PL, Hankinson JL, Irvin CG, et al. Guidelines for metacholine and exercise challenge testing-1999. Official statement of the American thoracic society. Am Respir Crit Care Med. 2000;161(1):309-29. https://doi.org/10.1164/ajrccm.161.1.ats11-99

PMid:10619836

30. National Institutes of Health, National Heart, Lung, and Blood Institute. Definition, description, and diagnosis of asthma. In: Global Initiative for Asthma: Global Strategy for Asthma Management and Prevention. United States: National Institutes of Health, National Heart, Lung, and Blood Institute; 2019. p. 1-11.

31. Gannon PF, Burge PS. Serial peak expiratory flow measurement in the diagnosis of occupational asthma. Eur Respir J Suppl. 1997;10:57-63

PMid:9098712

32. Kogevinas $M$, Anto $J$, Soriano JB, Tobias A, Burney $P$. The risk of asthma attributable to occupational exposures. A population based study in Spain. Am J Respir Crit Care Med. 1996;154(1):137-43. https://doi.org/10.1164/ ajrccm.154.1.8680669 PMid:8680669

33. Fishwick D, Perace N, D'Souza W, Lewis S, Town I, Armstrong R, et al. Occupational asthma in New Zealanders: A population based study. Occup Environ Med. 1997;54(5):301-6. PMid:9196450

34. Crane J, Lewis S, Slater T, Crossland L, Robson B, D'Souza W, et al. The self-reported prevalence of asthma symptoms amongst adult New Zealanders. N Z Med J 1994;107(988):417-21. PMid:7970336

35. de Meer G, Kerkhof M, Kromhout H, Schouten JP, Heederik D. Interaction of atopy and smoking on respiratory effects of occupational dust exposure: A general populationbased study. Environ Health. 2004;3(1):6. https://doi. org/10.1186/1476-069x-3-6

PMid:15175108

36. Romanet-Manent S, Charpin D, Magnan A, Lanteaume A Vervloet D. Allergic vs. non-allergic asthma; what makes the difference? Allergy. 2002;57(7):607-13. https://doi. org/10.1034/j.1398-9995.2002.23504.x PMid:12100301

37. Karadzinska-Bislimovska J, Cvetanov V, Petrovska J, Todorov S Risteska-Kuc S. Respiratory symptoms and positive skin prick test in a prospective asthma study in republic of Macedonia (initial results). Eur Respir J. 1999;14(30):78.

38. Wieringa $\mathrm{MH}$, Weiler JJ, van Bastelaer FJ, Nelen VJ, Van Sprundel MP, Vermeire PA, et al. Higher asthma occurrence in an urban than a suburban area: Role of house dust mite skin allergy. Eur Respir J. 1997;10(7):1460-6. https://doi.org/10.1183 /09031936.97.10071460 


\section{PMid:9230231}

39. Malo JL, Chan-Yeung M, Bernstein D. Asthma in the Workplace. $4^{\text {th }}$ ed. United States: CRC Press, Taylor \& Francis Group; 2013.

40. Karjalainen A, Kurpa K, Martikanen R. Work is related to a substantial portion of adult-onset asthma: Incidence in Finnish population. Am J Respir Crit Care Med. 2001;164:565-8. https:// doi.org/10.1164/ajrccm.164.4.2012146

41. Johnson AR, Dimich-Ward HD, Mantreda J, Klaukka T, Karjalainen J. Occupational asthma in adults in six Canadian communities. Am J Respir Crit Care Med. 2000;162(4):2058-62. https://doi.org/10.1164/ajrccm.162.6.9805079 PMid:11520716

42. Blanc PD, Toren K. How much adult asthma can be attributed to occupational factors? Am J Med. 1999;107(6):580-7. https://doi. org/10.1016/s0002-9343(99)00307-1 PMid: 10625027

43. Blanc PD, Ellbjar S, Janson C, Norbäck D, Norrman E, Plaschke $\mathrm{P}$, et al. Asthma-related disability in Sweden. Am J Respir Crit Care Med. 1999;160(6):2028-33. https://doi. org/10.1164/ajrccm.160.6.9901033 PMid:10588624

44. Leuenberger P, Schindler C, Schwartz J, Ackermann-Liebrich U, Tara D, Perruchoud AP, et al. Occupational exposure to inhalative irritants and metacholine responsiveness. Scand J Work Environ Health. 2000;26(2):146-52. https://doi.org/10.5271/sjweh.524 PMid: 10817380

45. Nemery B. Occupational asthma for the clinician. Breath. 2004;1(1):25-33.

46. Chen-Yeung M. Assessment of asthma in the workplace. ACCP consensus statement. American college of chest physicians. Chest. 1995;108(4):1084-117. https://doi.org/10.1378/chest.108.4.1084 PMid:7555124

47. Stoleski S, Minov J, Karadzinska-Bislimovska J, Mijakoski D, Atanasovska A, Bislimovska D. Asthma and chronic obstructive pulmonary disease associated with occupational exposure in dairy farmers-importance of job exposure matrices. Open
Access Maced J Med Sci. 2019;7(14):2350-9. https://doi. org/10.3889/oamjms.2019.630

\section{PMid:31592062}

48. Stoleski S, Minov J, Karadzinska-Bislimovska J, Mijakoski D. Respiratory symptoms, lung function impairment, and chronic respiratory diseases among crop farmers: Assessment by job exposure matrices. EMJ Respir. 2016;4(1):72-80. https://doi. org/10.1183/13993003.congress-2015.pa1180

49. Larbanois A, Jamari J, Delwiche JP, Vandenplas $O$ Socioeconomic outcome of subjects experiencing asthma symptoms at work. Eur Respir J. 2002;19(6):1107-13. https:// doi.org/10.1183/09031936.02.00272202a

PMid: 12108864

50. Tarlo SM, Leung K, Broder I, Silverman F, Holness DL. Asthmatic subjects symptomatically worse at work: Prevalence and characterization among a general asthma clinic population. Chest. 2000;118(5):1309-14. https://doi.org/10.1378/ chest.118.5.1309

PMid:11083679

51. Saarinen K, Uitti J, Tammilehto L. Work-related exacerbation of symptoms of established asthma: A population-based survey. Eur Respir J. 2001;18(33):277-8.

52. Plaschke PP, Janson C, Norrman E. Onset and remission of allergic rhinitis and asthma and the relationship with atopic sensitization and smoking. Am J Respir Crit Care Med. 2000;162(3):920-4. https://doi.org/10.1164/ ajrccm.162.3.9912030 PMid: 10988106

53. Vandenplas O, Toren K, Blanc PD. Health and socioeconomic impact of work-related asthma. Eur Respir J. 2003;22(4):85360. https://doi.org/10.1183/09031936.03.00053203 PMid:14582924

54. Vandenplas O, Malo JL. Definitions and types of work-related asthma: A nosological approach. Eur Respir J. 2003;21(4):70612. https://doi.org/10.1183/09031936.03.00113303 PMid:12762361 